Portland State University

PDXScholar

Engineering and Technology Management

Faculty Publications and Presentations

2007

\title{
Mergers and Acquisitions: Team Performance
}

Antonie J. Jetter

Portland State University, ajetter@pdx.edu

Richard Sperry

Portland State University

Follow this and additional works at: https://pdxscholar.library.pdx.edu/etm_fac

Part of the Engineering Commons

Let us know how access to this document benefits you.

Citation Details

Sperry, Richard; Jetter, Antonie J: Mergers and Acquisitions: Team Performance, in: Proceedings of PICMET 2007: Management of Converging Technologies, pp. 211-218 August 5-9, 2007, Portland, OR

This Article is brought to you for free and open access. It has been accepted for inclusion in Engineering and Technology Management Faculty Publications and Presentations by an authorized administrator of PDXScholar. Please contact us if we can make this document more accessible: pdxscholar@pdx.edu. 


\title{
Mergers and Acquisitions: Team Performance
}

\author{
Richard Sperry, Antonie Jetter \\ Dept. of Engineering and Technology Management, Portland State University, USA
}

\begin{abstract}
Many mergers and acquisitions in high technology do not yield the expected results and acquired technologies fail to create value as planned. One explanation is the difficulty to transfer and integrate the tacit components of technological knowledge, when work groups and teams are disrupted. Mergers force work group and team members to redefine their roles, change their working approaches, and develop a shared vision and culture. The paper therefore researches high-tech mergers from a team perspective through an exploratory case study of two formerly separate Quality Assurance groups that were integrated into one. The case study identifies three factors that impact team performance after a merger: strong vision, clear communication, and operational synergy built on an open team culture and a common working approach
\end{abstract}

\section{INTRODUCTION}

Technological innovations are the key to business success in high-tech industries. Corporations do not only create them internally, but also use outside sources and "buy" innovation though licensing, R\&D contracting and consulting, hiring away of key personnel or by taking over or merging with other companies. Mergers and Acquisitions (M\&A) play a major part in the business world. In 2006, over 3.8 trillion dollars were announced in transactions in the United States alone [15]. For major corporations, M\&A are not single events, but integral part of their business strategies. Since 2000, for example, Microsoft has acquired over 37 companies, EMC has acquired 17 companies, Google has acquired 25 companies, and Yahoo has acquired 27 companies. [3].

M\&A yields control over the existing assets (patents, product lines, and buildings) of the acquired company as well as the future value created through the capabilities (employees and their intellectual property) of the acquired company [7].

Studies indicate that somewhere between $50 \%$ and $80 \%$ of M\&A fail [22]. While some of these failures can be attributed to a misjudgment of the value of the acquired technologies [17], others are caused by the inability to fully exploit the intellectual property of the employees in the acquired companies, as teams are disrupted and team roles have to be redefined. Accordingly, Schweiger and Weber state synergy is a factor that contributes to the success or failure of a merger [21]. They also indicate people are affected by M\&A and there is often trauma and performance implications for both companies, as the integration of workforces means change that affects employee moral, especially when layoffs, turnover, and loss of key personnel are at stake. The acquiring company must therefore properly plan for change while sustaining value it acquired. Transition teams are essential in the integration [14], however they do not suffice, especially since change often appears successful at first, but after time it fails [10]. Larrson and Lubatkin indicate that in the long-term, fundamental change is necessary for M\&As to be successful and they state "Acculturation in mergers and acquisitions (M\&As) is the outcome of a cooperative process whereby the beliefs, assumptions, and values of two previously independent work forces form a jointly determined culture" [13]. They further state "achieving acculturation represents a major postacquisition challenge to acquiring firms."

This case study researches operational synergy between two independent work forces working together through the melding of cultures with two high technology companies. Specific emphasis is on the Quality Assurance (QA) organization because it was the first functional organization to merge work forces. The merger exceeded financial expectations of market share but failed in meeting the operational and budgetary objectives. The findings from this exploratory research support the notion of acculturation and synergy as important factors of the success of M\&A. The paper presents these findings with specific focus on work team performance. In addition to the introduction (Part I), it is structured in four parts: In part II, the characteristics and attributes of work group and team performance are defined. Part III describes the case study methodology for data collection and summarizes the observations in the QA organization. Part IV analyzes the findings and compares them to current supporting research. Part $\mathrm{V}$ discusses the findings and gives recommendations for areas for further empirical research.

\section{TEAMS}

In this case study, the members of the work force participate on project teams that produce new technology products or upgrades to the existing product line. Understanding what disciplines or characteristics that creates operational synergy was necessary for this research. Katzenbach and Smith identified basic disciplines that determine team performance. They indicate team performance depends on having a common purpose, common set of performance goals, a commonly agreed upon working approach, and they must hold one another mutually accountable [9]. 
In their research, they have characterized and identified various levels of performance, as shown in Figure 1 - Team Performance Curve, as adapted from [9 p84]. The higher the team performance the higher level of synergy is found among the team members. A work group, which is a very common structure in large organizations as project teams are formed with members from multiple matrix functional organizations. The primary characteristic that sets the work group apart from a real team or high performance team is that the work group's focus is on individual deliverables or contributions, where as a real team or high-performance team has a common purpose, performance goal, and working approach, and a team members are accountable to one another.

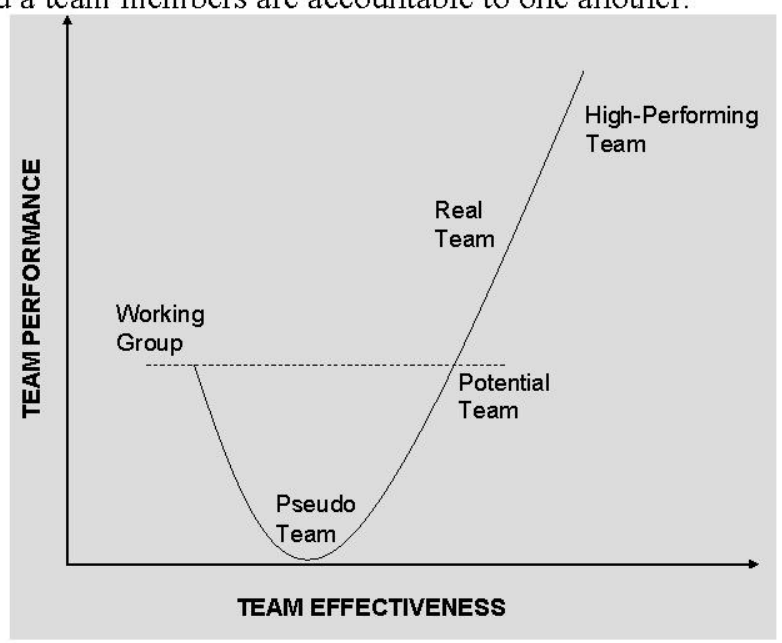

Figure 1 - Team Performance Curve

Katzenbach and Smith have broken down teams into pseudo, potential, real, and high performance. A pseudo team is the worst performer of all. A pseudo team is a dysfunctional group of individuals who have called themselves a team with no common purpose or performance goals. A potential team, on the other hand, tries to achieve performance goals. However, it is weak in developing a common working approach and it has not established a sense of accountability to each of the team members. A real team has established common working approach and is accountable to each member on the team, in addition to having a common purpose and performance goals. A high performance team goes one step further in that they deeply committed the personal growth and success of the each other.

\section{CASE STUDY}

\section{A. Methodology}

The methodology consisted of researching and designing an interview guide with questions that would probe team and group performance. The information from the interviews was recorded for consistency and populated in a spreadsheet for data analysis.

\section{1) Research Questions and Design}

The purpose of this research was the exploration of the impact of mergers on work groups and teams. Questions of interest included, but were not limited to the following: How do work groups and teams experience the change associated with a merger? How do the defining characteristics of a team described in the previous section evolve over time? How do the merger and the subsequent changes affect employee's ability to function effectively as a team and create value? Do high-tech companies, on the team level, actively manage the process of acculturation after a merger?

For the exploratory first step of this research, a total of three case study companies were selected based on the following criteria (1) high technology product that requires expert knowledge, (2) merger aims at the integration and further growth of value assets from both companies, (3) some experience with M\&A as a strategic choice. Criteria 2 and 3 were chosen to exclude M\&A activities that are planned to result in the discontinuation of one company's value assets and mergers that are "one-time-events," with no established management practices.

Open-ended interviews were conducted in all three case study companies, capturing different team-members perspectives on the merger. An interview guide was created to ensure consistent and structured data gathering process for all interviewees. The interview portfolio was structured into five areas of research: Purpose and Goals; Working Approach; Accountability; Commitment to Growth and Success, and External Impacts. External impacts looked at culture, policies, and retention of individuals. Each of these areas was chosen because they probe and ascertain specifics characteristics on organization team performance as well as task and human integration and its impact on the operational synergy [4].

The case study will be further discussed in the following sections. To protect the privacy of the company, the names of the case study company and the people involved have been altered; however, the pertinent information remains true and all explanations of events and outcomes is factual.

\section{2) Data Collection}

The case study company, FINCorp, is a leading fortune company 500 listed on the NYSE. The company provides financial data processing services to more than 16,000 clients worldwide, including banks, credit unions, financial planners/investment advisers, insurance companies and agents, self-insured employers, lenders, and savings institutions with over $\$ 3.4$ billion in processing and services revenues. FINCorp has 87 business units, which operate as separate businesses. Many of these businesses were the result of mergers and acquisitions.

FINTran, a business unit of FINCorp, is one of the fastestgrowing financial data processing businesses within FINCorp. In January of 2003, FINTran announced the acquisition of Financial Data Services (FDS), who is a 
competitor in same market. FINTran's revenue in 2003 was over $\$ 68$ million and FDS was over $\$ 140$ in revenue. A summary is provided in TABLE 1: A DESCRIPTION OF THE CASE STUDY. In addition to processing financial transaction product line, FDS also operated a network that connected acquirers and issuers of these financial transactions. The business objective for the acquisition thus was market share and growth. At the time of acquisition, both organizations had between 1,300 and 1,400 clients each. However, it was the TranX network that was growing rapidly and presented a new customer base to FINTran to fill the void in a mature market place.

Unlike acquisitions where the acquiring organization swallows up a smaller organization, it was the opposite in this case: FINTran serviced their clients with 235 employees, while FDS had 647, at the time of the acquisition. FINCorp chose not let FDS run as one of its 87 separate business unit, but rather chose to absorb FDS into FINTran. The integration of the two companies resulted in an executive management team with key executive management personnel from both companies. The FINTran CEO remained as $\mathrm{CEO}$, while the $\mathrm{CEO}$ of FDS became the COO. Strategic planning, financial reporting, and budgetary requirements were conducted under the umbrella of the FINCorp.

TABLE 1: A DESCRIPTION OF THE CASE STUDY

\begin{tabular}{|c|c|c|}
\hline 2003 & $\begin{array}{c}\text { FINTran } \\
\text { (Business Unit of } \\
\text { the Acquirer } \\
\text { FINCorp) }\end{array}$ & FDS (Acquired) \\
\hline Revenue & $\$ 68$ million & $\$ 140$ million \\
\hline Client Base & $1300-1400$ & $1300-1400$ \\
\hline Employees & 235 & 647 \\
\hline Product Line & $\begin{array}{c}\text { PCI: Transaction } \\
\text { Processing } \\
\text { Services }\end{array}$ & $\begin{array}{c}\text { NOAC: } \\
\text { Transaction } \\
\text { Processing } \\
\text { Services }\end{array}$ \\
\hline & \multicolumn{1}{|c|}{ QA } \\
Interviews & $\begin{array}{c}\text { TranX: } \\
\text { Network }\end{array}$ \\
\hline & $\begin{array}{c}\text { 2 Manager } \\
3^{\text {rd }} \text { Party Observer }\end{array}$ & $\begin{array}{c}2 \text { QA Analysts } \\
3^{\text {rd }} \text { Party Observer }\end{array}$ \\
\hline
\end{tabular}

The merger has met and partially exceeded management's business objective by turning FINTran into a market leader with operations expanding world wide with revenues exceeding \$230 million in 2006. It did, however, not meet the financial operational and budgetary objectives and timelines to merge and integrate workforces. After 3 years it is was still riddled with organizational issues that were particularly evident in the Quality Assurance (QA) department, which was the focus of the case study. The QA department was chosen because it was the first functional organization that attempted to merge operations from both companies into a single organization. The interviews consisted of eight individuals. One of the interviewee's was the QA manager. The QA manager was an employee of FINTran, the acquiring company, and was responsible for merging both QA departments into one organization. Two interviewees' were $\mathrm{QA}$ analysts from FDS, the acquired company. Another two interviewees' were QA analysts who were employees of FINTran the acquiring company. Two additional interviewees' were outside consultants who acted as thirdparty observers, as they had no allegiance to either organization. The last interviewee was with the Executive Vice President (EVP) of Human Resources who was heavily involved defining the integration process and employee polices, which included benefits and layoffs. In addition, the EVP was a member of the integration team.

Several of the interviewees had been involved with other mergers and acquisitions which provided additional insight into the findings. Of particular interest was one interviewee, currently working at FINTran, who actually work for FDS when their company was acquired by FDS, but left due to the integration issues.

Each interview took approximately 1 to 2 hours in length with additional follow-up questions and observations on work processes themselves. The raw interview information was captured on a voice recording machine and placed into a spreadsheet. The voice recorder allowed playback of the interview to accurately reflect the interviewees' comments. The spreadsheet facilitated data analysis by sorting and dissection of acts or events.

\section{B. Description of Findings}

The data analysis was broken down by those disciplines that differentiated the level of performance and synergy of team performance as identified by Katzenbach and Smith. The results of the findings are presented in the following subsections.

\section{1) Common Purpose and Goals}

The executive team was a combination of both FINTran and FDS key management personnel. The dynamics between the $\mathrm{CEO}$ and $\mathrm{COO}$ in combination with separate product lines created a mixed environment. It was unclear as to who was in control, FINTran or FDS. In fact, the employees referred to each side of the organization in terms of the transaction processing product line, PCI (FINTran) and NOAC (FDS). This created a division, or in some cases a civil war amongst employees.

In the initial 2 years, the FINTran and FDS QA organizations were managed separately. The reason given was because the skills were different to support the PCI and NOAC product lines and this contributed to them not understanding the company's vision. They attributed this to both products were being offered and sold by separately. As a result, they were unsure about the company's purpose and goals. One of the interviewees mentioned that in the initial stages of the integration process the executive management indicated the NOAC is the product line of choice; however, 
both product lines remain today with no clear vision for the future. This has led to more questions and uncertainty.

Everyone knew integration between the products was no small task. Additionally, the company was focused on adding new products to compete in the market space. These new products were duplicated on both product lines; thereby increasing the cost of ownership. The lack of product vision continues to fuel the "us" vs. "them."

Both QA organizations indicated at the functional organizational level, their purpose and goals were understood as they remained the same; being committed to assuring the code base is defect free. Each organization conducted their QA testing independently with no overlap. This was primarily due the different skills sets and knowledge required for testing. FINTran's PCI product line is comprised of thirdparty vendor software with minimal customization, where as the FDS NOAC product line is heavily custom software.

In the summer of 2005 , the COO left the organization to run another business unit in FINCorp. Within weeks of the announcement major changes were made at the executive management level as well their direct reports. This sent a clear message to all employees that FINTran was one company and will be led by one CEO. As result, both QA organizations were merged under leadership of the FINTran's QA manager. The manager reaffirmed that the merged QA organization still had one common goal, which was defectfree code. This was reassuring to all. It was also communicated to both QA organizations that no changes would be made right away. The manager visited all QA employees at their location to listen and gain insight into the issues still at hand, and learn more about the operations and working approach.

\section{2) Common Working Approach}

Before and during initial years of the acquisition, both QA organizations had completely different approaches to testing. The FINTran organization conducted their testing in a semistructured environment. They were handed code from research and development (R\&D) ready to test. They used the high-level design that was created by $R \& D$ to create test scripts. Once testing was completed, they handed the code back to $R \& D$, who was then responsible for managing the installation in cooperation with the data center and network operations.

On the other hand, FDS had a very structured formal project management process based on CMM best practices. Their approach to testing included formal test plans and test scripts, which were based on approved business requirements, business design (user interface and report layouts), and technical design specifications. The process also required design specifications and requirements to be approved by Sales, Development, QA, Operations, and Implementation at each step in the project lifecycle.

In the last quarter of 2004, the more formal FDS project management processes were introduced throughout the enterprise. This signaled that FDS has won the battle and led to resistance of the working approach as well as uncertainty within the FINTran organization. Although the FINTran recognized the need for these more formal processes, the FINTran analysts commented the process and documentation was overwhelming for them. One such comment was "it takes 4 hours to document a 5 minute task."

The formal project management process required QA analysts be active members in the development project, from requirements definition through installation, and provide support in diagnosing production issues. This resulted in the FINTran QA analysts becoming more involved in each step of the project and even began to manage the release into production; thereby extending their responsibility and authority.

In the first quarter of 2005 , management approved an initiative that required the integration between the PCI and NOAC product lines, thereby forcing a "limited" cooperation among both QA groups. For the most part, product line testing still remains as separate activities and the issue of control still exist.

By 2006, the growth of the company has resulted in approximately 600 new clients, with 105 active projects with aggressive client commitments, and another $90+$ projects to be started. Both sides now believe areas of the project management process is breaking down as QA is seeing contention for the same code base, thereby creating dependencies among projects and creating delays to acquire the code base to test.

\section{3) Mutual Accountability and Commitment to Success}

Despite the "us vs. them" mentality that exists, the QA analysts are committed to their profession so the acquisition did not change that commitment or their accountability to each other. Their professional motivation was to ensure defect-free code. The two organizations just had different approaches and methods. The FINTran organization always performed integration and system testing before releasing code to production. This forced accountability among the FINTran QA analysts to ensure defect-free code and that one component did not affect another. On the other hand, the NOAC product line was heavily customized with many components. FDS QA Analysts had specific component knowledge and their testing tasks were aligned by system component. It was typical on the NOAC product line to move individual components into production at different times.

As mentioned above, the cross-product line project required the PCI QA environment to include NOAC platform functionality. In the beginning, it was made perfectly clear that the building of the NOAC functionality in PCI QA environment would be done by a FDS QA analyst to ensure the NOAC functionality was properly built. This decision signaled a lack of trust and commitment amongst the FINTran QA analysts. Due to time constraints, a FINTran QA analyst had to build the environment with consultative 
support from the FDS QA analyst. At the completion, the FINTran and FDS QA analysts saw this as a galvanizing event that broke down a wall between the two organizations and set the tone for joint commitment to success and accountability in getting the job done without organizational ties.

\section{INTERPRETATION OF FINDINGS}

The analysis of the case described above shows three reoccurring themes that seemed to have played a role for the productivity of a merged project team: the lack of a strong vision, deficiencies in communication, and the absence of operational synergy. They will be further discussed in the following sections.

\section{A. Vision}

Kotter indicates a clear vision is required any time changes are made in a team, especially during integration after a company acquisition [10]. Kotter identifies that a vision has three primary outcomes:

1) Sets the direction for change

2) Motivates people to help them overcome resistance

3) Coordinates the actions of the individuals.

Kotter also emphasizes creating a vision requires participation from the managers who have a stake in the new team. Once the vision is defined, those managers must be role-models of that vision for the rest of the team.

It was observed the new executive management team did not take the time to create a clear vision. As mentioned, management hinted that NOAC was the product line of choice, but clearly this was not the case as the two products continue to exist in the same market space. Skipping the vision setting, results in organizations that are not motivated toward any direction and are therefore in constant conflict [10]. In addition, the lack of a clear vision fostered uncertainty as to who was in control: The FINTran employees believed they were in control since they acquired FDS. On the other hand FDS thought they were in control because the FDS project management process was being implemented enterprise wide, in addition to rumor that NOAC was the product of choice. This ended up with a lack of manger buy-in and ultimately an unsuccessful integration that created an "us" vs. "them" attitude.

When the shared vision is finally defined and communicated, each person committed to fulfilling that vision will be able to picture what life will be like when the vision is complete [10]: Having a common vision that everyone understands and works toward reduces unnecessary work, duplication of effort, and conflict amongst the team members from the acquired and acquiring companies.

\section{B. Communication}

Organizational communication to employees is possibly one of the most important and yet commonly overlooked instrument for engendering identification [20]. Stakeholder communication is important in every type of project as it builds a strong team and often delays in project and even failures can be attributed to poor communication [1]. When communication is strong there is no confusion - goals are known and clear [10]. The type of communication varies depending on the phase of integration between two companies - pre-merger or planning, initial integration, or full-swing post-integration as employees needs change due to uncertainty and insecurity [8]. Communication becomes more critical during the integration as employees experience the affects of the M\&A; therefore, it is important to continually communicate the value of the M\&A and how the employees will fit into the organization [19].

Although, this case study did not directly deal with the pre-merger announcement, literature suggests when an organization first learns of the merger or acquisition the employees natural reaction is ask how this will impact them. The main goal of communication is to diminish uncertainty as found Schweiger's and Denisi's study of two plants (controlled and experimental) [18]. In their study they observed there is a negative impact due to uncertainty. Specifically, as uncertainty increases so does stress. In addition, satisfaction decreases along with the interaction and commitment to remain with the organization. They further indicate that realistic communication in the form of the merger preview in the planning stage helps employees through this process.

Therefore, it is better to be upfront than to not say anything. Messmer indicates, "even if you don't have all the facts yet, discuss all of what you are allowed to reveal, including issues that are under consideration and the timeline for decisions [16]." Messmer also states "Early communication is critical in any merger or acquisition situation. If employees receive the initial word of change without immediate follow-up information, the rumor mill will undoubtedly start turning." $\mathrm{He}$ goes on and further recommends getting your staff involved by soliciting their feedback and ideas. The manager should communicate as openly as possible to maintain the team trust and to encourage the team to communicate openly with him or her. If the manager is too secretive, then the team is left to make his or her own assumptions, which are generally more pessimistic than reality [2] [5].

Once the integration phase begins, this period of transition is critical to maintain communication for building a strong organization. It should be very clear who is in control. Just as the FINTran case shows, when people were unclear who was in charge they tend to retreat to their comfort zones and rely on old procedures [2]. Immediately following the acquisition, higher-level management and the direct manager needs to reinforce and communicate the value of the M\&A 
and its impact on both the acquired and acquiring employees. As Messmer indicated, the manager does not need to have an integration plan. To minimize impact and feel value, people need to continue doing what they were doing prior to the acquisition until the new strategy is developed. By soliciting feedback and making people feel have a purpose the manager can help to restore their sense of worth and maintain their productivity [15] [19].

There is no prescribed set time for how long the integration will take. It does vary by the type of innovation or value expected from the project team [7]. For full integration of radical innovation, the period will take longer than if only partial integration and incremental innovation are expected [7]. Initial integration needs to allow for sufficient analysis and understanding but should not drag on unnecessarily. During this time, project team members are waiting to see how they will fit into the new team. This is where a manager with clear and strong leadership must be present. During this time, no major changes will occur, but extensive time will be spent in a period of analysis. The manager should be building communication channels, which should start from the very beginning and be ongoing [11]. Established clear and effective channels of communication will aid the manager in understanding the core competencies of each team and the individual strengths and weaknesses of project team members, as well as hearing and addressing their needs and concerns [11].

As in the case of with the two QA organizations, the FINTran QA manager decided to listen before making any decisions and restated the existing QA purpose and goals. It was also observed, waiting too long can lead to a feeling of alienation in the project teams and also encourage an "us-vs.them" attitude. Once these team divisions start to strengthen, the barriers can be very difficult to break down.

The initial integration phase should complete with a strong enough understanding of the big picture and the details that the manager can develop a strategy for merging the projects and building an effective team. Once sufficient analysis and understanding is taken, it is time to move toward full integration and the building of cooperative processes that minimizes weaknesses while leveraging strengths. The strategy must support the goals and objectives as defined by the vision of the larger organization, and those financial and value creation goals that were intended to be attained through the acquisition. Clearly, the lack of vision by FINTran made this difficult.

According to Jemison and Haspeslagh, communication challenges to be addressed throughout integration include the following points [7]:

1. Establishing interface management

2. Putting operations on an even keel

3. Instilling a new sense of purpose

4. Taking stock and establishing control.

5. Strengthening the acquired organization

6. Developing mutual understanding
7. Building credibility up and down.

\section{Operational Synergy}

Operational synergy is based on organizations' culture and common working approach.

\section{1) Culture}

Acculturation requires two companies coming together and creating cooperative processes-based beliefs, assumptions, and values [13]. Larson and Lubatkin point out that although it may be popular to blame M\&A failures on cultural difference, their studies have found acculturation depends on the "social controls" or the amount of coordination efforts expanded by the buying firm. Two companies don't simply clash because of their cultural differences. It is when the acquiring company imposes formal integrating controls on its acquired firm's culture that it is less likely acculturation will be achieved. Conversely, the more informal social controls or shared experiences used, the more likely acculturation is achieved. They also found removing autonomy is not always an impediment to achieving acculturation as long as it is coupled with a high level of informal control and it was non-authoritarian. Birkinshaw et al found long-term success is achieved through process management, communication, and sensitivity to the concerns and expectations of the employees on both sides of the M\&A [4]. Therefore, informal social controls, such as such as training programs, site visits, and celebration or socialization rituals are needed to support process management, communication, and concerns and expectations of the joint work forces.

It is interesting to note, from the outset FINCorp decided to integrate the two companies and that key FDS executives would join the FINTran executive management team. Because FDS was not left to be it is own business unit and there was the formation of joint executive management team, FINCorp was signaling to FDS it had to maintain and comply with the FINTran strategic planning, financial reporting, and budgetary requirements. This implied a level of restriction to FDS or removal of autonomy [13]. In 2005, when the COO left, the changes in management in combination with merging the organizations, FINTran further signaled to FDS that autonomy was not longer tolerated and FINTran management was in charge.

Synergy between the work forces is required to ensure a successful working relationship and environment. The "usvs.-them" attitude suggested a clash between FINTran and FDS cultures. However, despite this tension and "us-vs.them" attitude, FINTran did achieve its objective of market and growth. This may be part in due to FINTran and FDS being in the same industry. Trompenaars and Prud'Homme state there are four types of organizational culture: competitive, formal, individualistic, and democratic [21]. All companies have a culture dominant in one of these areas with small elements of the others. The change in two merging cultures happens gradually over time and cannot be forced. 
This also suggests that at the lower levels, such as QA analysts, they were able to get past the tension and jointly unify forces to create joint or mutual accountability using informal social controls, thereby supporting Larson and Lubatkin concept of informal social controls. The level of success from the galvanizing event with the building of the NOAC components within the PCI environment, signaled a real team can come together when there is mutual accountability [9] [13].

\section{2) Working Approach}

The working approach is one of interest. An effective team is one that understands and has developed a common approach to working with one another to accomplish their vision [9]. In the initial years, the two QA organizations were left to operate autonomously in physically remote locations. Skill-based strategic capabilities are often difficult to transfer primarily due to the knowledge, procedures, and culture that are imbedded within the team [6] [7]. Haspeslagh and Jemison further indicate the more complex the capabilities are, the longer it will take for the acquiring individual or team to learn those skills, as was proved true in FINTran case study. This decision to keep the two QA groups autonomous and maintain a decentralized environment as not loose knowledgeable resources resulted in operational synergies, which was never achieved.

At the end of 2005, FINTran QA had to adopt the FDS project management processes. The project management processes instilled formal and structured social controls. Although the FINTran QA determined a need for a more structured approach, there was not a sense of commitment to this new approach and as a result, productivity decreased. Reasoning suggests that moving to a single set of processes without a clear understanding of how it supports the organization's purpose and performance goals led to confusion and tension within the FINTran QA organization. As indicated previously, Larsson and Lubatkin contend that formal hierarchical controls threaten the social controls and that coordination efforts require social controls that are nonauthoritarian and informal, and show characteristics of strong cooperation, informal communication and teamwork [13].

Productivity is gained when the information is shared when helping each member cross areas of responsibility. This is a common characteristic of mutual accountability and a real team working together [9]. The informal social controls presented by the QA analysts worked effectively to break down walls, as signified by the galvanizing event in the building the NOAC functionality within the PCI QA environment. It also signaled that employee or team member empowerment will eliminate barriers [10]. As a result, operational synergy was created between the two organizations.

Jemison and Haspeslagh have outlined the following considerations that should be taken before integrating teams, which have been executing with separate working approaches include [7]:

1. When value creation is deemed a strategic objective to be been gained from an organization's culture it is best to understand the culture and its capabilities first, before the transformation to the other culture. This applies to both organizations transferred to another culture. First each firm must learn about the other, and then all must learn about the capability to be transferred.

2. Enabling the willingness of people on both sides to work together. This requires eliminating the feeling that job security, and control over resources and direction is lost when one side or the other feels they have "won" the battle.

3. It is necessary to identify and not assume the capabilities of the acquired organization before the transformation.

4. A clear alignment of project (team) goals to corporate goals is necessary to give a clear understanding of how they impact the overall strategy. By understanding their purpose and goal, the expected results from their tasks is understood as well as its importance.

\section{CONCLUSIONS AND RECOMMENDATIONS FOR FURTHER RESEARCH}

FINTran was successful in achieving its business objective of market share and growth, but failed in meeting its financial operational and budgetary objectives for integrating work forces. It stands to reason that FINTran's market share and growth increased by having two product lines and a combined customer base. Conversely, the cost of ownership of maintaining staff to support two product lines in the same market space exceeds the costs and ownership of one integrated product line. Furthermore financial, operational and budgetary integration was not achieved as fast and as completely as planned. This case study offered insight into the integration process and its problem areas:

Alhough FINTran's CEO was in charge and the former FDS executives had to share responsibilities with other FINTran executives as an attempt to remove autonomy, it was not clear. Maintaining and selling of two product lines fostered two separate organizations with different skills sets at different locations. This made it very difficult to remove autonomy from the formerly independent FDS. Poor communication and lack of a clear vision by executive management led to confusion as did the lack of a common purpose, thereby fostering an "us-vs.-them" attitude. When the $\mathrm{COO}$ left, who originated from FDS, the current management team sent a clear signal that integration was a mandate and FDS's autonomy will be removed.

The division of skills and product lines furthermore did nothing to instill a common working approach. When a common project management process was implemented, it was filled with formal controls that were met with resistance. The QA manager took the time and effort to listen, analyze, 
and build communication channels, while reassuring department purpose and goals; however, little was done to build operational synergy between work forces. Although the lack of a vision made it difficult, operational synergy could have been accomplished by bridging of skills and knowledge across the two product lines. This is evident by the limited project that not only bridged skills and knowledge, but it also created mutual accountability and commitment to success as result of combined product effort.

This case study identified several barriers 1) lack of a clear vision and understanding of purpose 2) separation of skills and ownership, and 3) no common working approach that was understood. The current body of research on communication, vision setting, and performance goals is quite extensive, but leaves questions unanswered. How can two merged organization create and communicate a clear vision when all pieces of the M\&A may not be understood at the time of integration? In addition, what levels of social controls are needed for integration of workforces and cultures and at what level of autonomy is required? While these problem areas are explored in this paper, the answers provided are limited in scope. With further empirical research into these questions and issues, the functional manager or team leader will have a greater understanding and implementing operational strategies and will not be powerless; as all of these factors can be managed throughout the acquisition process.

\section{ACKNOWLEDGMENT}

We would like to acknowledge Andrea Fox and Tom Litterer for their contribution to this research.

\section{REFERENCES}

[1] "A Guide To The Project Management Body Of Knowledge", Project Management Institute, $3^{\text {rd }}$ Edition, 2005

[2] Amabile,T., and Conti, R.; "Changes in the Work Environment for Creativity During Downsizing," Academy of Management Journal, vol. 42, no. 6, pp630-640, Dec 1999

[3] Bell, K.; "Managing Change During Periods of Mergers And Acquisitions"; UW Computing and Communications Graduate School Research

Paper, http://students.washington.edu/kbell/mergersacquisitions.html; January 29,2007
[4] Birkenshaw, J., Bresman, H., and Hakanson, L,; "Managing the PostAcquisition Integration Process: How the Human Integration and Task Integration Processes Interact to Foster Value Creation"; Journal of Management Studies, vol. 37, no. 3, pp395-424, May 2000

[5] Buono, A.F., and Bowditch, J.1.; "Ethical Considerations in Merger and Acquisition Management: A Human Resource Perspective", Sam Advanced Management Journal, Autumn, vol. 55, no. 4, pp18-23, 1990

[6] Cordero, R,; "Developing the Knowledge and Skills of the R\&D Professionals to Achieve Process Outcomes in Cross-Functional Teams", The Journal of High Technology Management Research, vol. 10, no. 1, pp 61-78, 1999

[7] Haspeslagh, P., and Jemison, D.; "Managing Acquisitions: Creating Value Through Corporate Renewal", New York: Free Press, 1991

[8] Jan Michielsen. Class Lecture, Topic: "Discussions of HR related Management Issues." CAP 1100, Guest Lecture ETM 510, Portland State University, Beaverton, OR, May 22, 2006.

[9] Katzenbach, J.D. and Smith, D.K.; "The Wisdom of Teams", Harper Essentials, 1999

[10] Kotter, J. P.; "Leading Change", Harvard Business Scho0l Press, Boston, MA

[11] Kotter, J.P.; "Realizing Change", The Interactive Manager Series, Harvard Business School Publishing, 1997

[12] Kreiner, K., and Lee, K.; "Competence and community: postacquisition learning processes in high-tech companies", International Journal Technology Management, vol. 20 , no. $5 / 5 / 6 / 8,2000$

[13] Larsson, R. and Lubatkin, M.; "Achieving acculturation in mergers and acquisitions: An international case survey", Human Relations, Vol 54 (12), pp 1573-1607, SAGE Publications, London, Thousand Oaks CAR, New Delhi, 2001

[14] Marks, M.L. and Mirvis, P.H; "Managing Mergers, Acquisitions, and Allinnces: Creating an Effective Transaction Structure"; Organizational Dynamics, vol. 28 , no. 3 , pp35-47, Winter 2000

[15] "Merger and Acquisition Report", SourceMedia, Inc, NY, New York, vol. 20 , no 1 , January 8,2007

[16] Messmer, M.; "Leadership Strategies During Mergers and Acquisitions", Strategic Finance, pp15-16, January 2006

[17] Moore, G.A.; "Crossing the Chasm", HarperBusiness Essentials, New York, NY, pp9-25, 1991

[18] Schweiger, D. M. and Denisi, A.. S.; "Communication with Employees Following a Merger: A longitudinal Field Experiment", Academy of Management Journal, Vol. 34, No. 1, pp110-135, 1991

[19] Schweiger, D.M., and Weber, Y.; "Strategies for Managing Human Resources During Mergers and Acquisitions: An Empirical Investigation"; Human Resources Planning, vol. 12, no. 2, pp60-86, 1989

[20] Smidts, A., Pruyn, H.Th., vanRiel, B.M; "The Impact of Employee Communication and Perceived External Prestige on Organizational Identification", Academy of Management Journal, vol. 48, no. 3, pp1031-1062, 2001

[21] Trompenaars F., and Prud'Homme, P., "Managing Change Across Corporate Cultures", John Wiley \& Sons, 2004.

[22] "Why Do So Many Mergers Fail?"; http://wharton.universia.net/index.cfm?fa=viewArticle \&id=927\&langu age $=$ english\&specialId $=$ 